\title{
An improved semiautomatic segmentation approach to land cover mapping for identification of land cover change and trend
}

\author{
M. T. H. Shubho $\cdot$ S. R. Islam • \\ B. D. Ayon · I. Islam
}

Received: 20 December 2013/Revised: 10 May 2014/Accepted: 8 July 2014/Published online: 25 July 2014

(C) Islamic Azad University (IAU) 2014

\begin{abstract}
Worldwide, land cover change is monitored by conventional land cover mapping techniques using satellite imagery. Index method ends with assigning positive values to indicate vegetation, wetland and built-up area. However, not all positive values up to a certain threshold specify desired land cover and might indicate other covers erroneously. Therefore, a threshold value must be determined above which land covers are mapped more accurately. In this research, we employed an improved land cover mapping technique to extract vegetation, wetland and built-up area using semiautomatic segmentation approach. We used double-window flexible pace search technique not only for built-up features but also for vegetation and wetland mapping to increase the accuracy. Study is based on Landsat Thematic Mapper images of 1989, 1999 and 2010 with spatial resolution of $30 \mathrm{~m}$. Integration of simple recoding of derived index images prior to threshold identification entails increased accuracy. Accuracy assessment of land cover mapping is done using high-resolution Google Earth satellite image which substitutes expensive aerial photography and time-consuming ground data collection. Error matrix presents 82.46, 96.83 and $90 \%$ user's accuracy of mapping built-up area, vegetation and wetland, respectively. Trend analysis discloses an average loss of vegetation and wetland by 2,664.6 and 5,328.8 acres per year, respectively, in study area from 1989 to 2010. Expectantly, future land cover mapping in similar researches will be greatly assisted with the diligent technique used in this study.
\end{abstract}

M. T. H. Shubho $(\bowtie)$ · S. R. Islam · B. D. Ayon · I. Islam Department of Urban and Regional Planning, Bangladesh University of Engineering and Technology, Dhaka 1000, Bangladesh

e-mail: 15tanvir89@gmail.com
Keywords Accuracy assessment · Double-window flexible pace search · Error matrix · Geographic information system - Land cover mapping - Remote sensing $\cdot$ Semiautomatic segmentation approach

\section{Introduction}

Land cover, in a concrete sense, can be defined as observed physical and biological cover on earth's surface (European Communities 2001). Vegetation, wetland and built-up areas are the dominant and broad land cover classes (Anderson et al. 1976). Different environmental change such as loss of vegetation and agricultural land, wetland filling and urban expansion can be indicated by land cover change (Turner et al. 1995; Lunetta 2002). Therefore, monitoring land cover change is required by the state authority for policy formulation, decision makers, planners, scientists and others (Yuan et al. 2005). These land covers have unique spectral reflectance at different wavelengths which enables them to be distinguished readily from each other in satellite imagery (Sanderson 2000). Hence, various methods have emerged to map land cover classes in satellite image to detect the trend of their change with time.

Remotely sensed images are useful to provide opportune and synoptic views of land cover (Guindon et al. 2004; Xu 2008; Bhatta 2009; Griffiths et al. 2010). During the last two decades, researchers have increasingly come up with various remote sensing techniques to map land covers using different satellite imagery (Rogan and Chen 2004). Techniques for automatically mapping land cover classes are based on either classification of satellite images (Guindon et al. 2004, Cleve et al. 2008) or direct segmentation of indices (Zha et al. 2003, Zhang et al. 2005). However, overlapping character of land features together with their spatial and spectral variability 
poses challenges to accurately map them in remote sensing imagery. In quest of a more accurate extraction of built-up features, He et al. (2010) proposed a modified Normalized Difference Built-up Index (NDBI) approach of the original offered by Zha et al. (2003). This approach uses semiautomatic segmentation technique of Chen et al. (2003) which includes identification of an optimum threshold value. However, in case of vegetation and wetland extraction using indices, identification of threshold value is usually not practiced (Rouse et al. 1974; Huete 1988; Xu 2007). Therefore, efforts to integrate threshold identification also into the vegetation and wetland indices for more accurate mapping in satellite imagery are worthwhile.

In light of the above discussion, this study made an attempt to use semiautomatic segmentation approach to map three land cover classes in Landsat Thematic Mapper (TM) satellite images. The technique used in this research incorporates a simple additional step 'recoding' prior to identification of optimum threshold value for each index. Consequently, desired land cover is mapped above the determined threshold value. These produced maps of classified land covers are not very useful without quantitative statements about their accuracy (Maling 1989; Janssen and Vander Wel 1994; Campbell and Mortenson 1989; Smits et al. 1999). Therefore, accuracy assessment is performed in almost all similar researches, (Muller et al. 1998; Xu 2007; He et al. 2010). However, it is not always possible to take ground truth data for vast area or afford high-resolution aerial photography or IKONOS and SPOT satellite images to assess the accuracy of land cover mapping. Therefore, in this study, accuracy assessment is performed using easily available and cost free Google Earth satellite image.

The research techniques were applied to the Dhaka city, the capital of Bangladesh, and its surroundings. There is no concrete data on the loss of vegetation and wetlands outside Dhaka supported by any academic or institutional research. In this backdrop, this study is also the first attempt to identify the land cover change due to the conversion of vegetation and wetland into built-up area in the periphery of Dhaka city. The research was carried out in the department of Urban and Regional Planning of Bangladesh University of Engineering and Technology from November 2012 to January 2013.

\section{Materials and methods}

Study area and data

Dhaka, the capital city of Bangladesh, is one of the most overly populous megacities in the world (Shubho et al. 2013). Extreme development pressure inside Dhaka metropolitan area is inducing development outside the city in a careless unplanned manner. Such developments are going on a large chunk of agricultural lands and wetlands (IRIN 2012; Wardad 2012; Priyodesk 2011). However, the absence of research data on the present scenario of Dhaka's outside development has made the concerned authority as well as the general citizen oblivious of the loss of vegetation and wetlands. Therefore, an attempt was made to discover the trend of loss of agricultural lands and water bodies around Dhaka city. Reconnaissance survey revealed that maximum Real Estate Development (RED) projects immediately outside Dhaka city were within $10 \mathrm{~km}$ from Dhaka Metropolitan Development Plan (DMDP) boundary. Therefore, a buffer of $10 \mathrm{~km}$ around DMDP boundary was constructed using ArcGIS. This buffer area with $2,020 \mathrm{~km}^{2}$, was selected as study area.

Landsat-5 TM images were collected from Global Land Cover Facility (GLCF) and SPARRSO. GeoTiff images from Worldwide Reference System (WRS-2) of Path 137, Rows 43 and 44, were collected which includes the study area (Fig. 1). Available satellite images were not of the same date of same year for Rows 43 and 44. Therefore, images of same season but different year gap were used. For instance, satellite images of 1989 and 1991 have been used as an image of single year represented as 1989 (Table 1).

\section{Data processing}

\section{Image Mosaicking}

Following fundamental image preprocessing, data were further processed to facilitate the operations ahead. Since the study area is contained within the images of two separate rows -43 and 44 (Fig. 1a), it became necessary to mosaic the images of two rows to create a single raster image. To do this, ArcGIS 10 was used. During the process of mosaic, a certain strip of overlapping area generates which is common to both images. This overlapping area creates uncertainty as for different images the Digital Number (DN) values are different. Besides, the rotated raster image contains ' 0 ' values where there is no data (Firl 2010). To get over the uncertainty, 'Maximum' was chosen as 'Mosaic Method'. With this option, the output cell value of the overlapping areas became the maximum value of overlapped cells and the ' 0 ' value got omitted. 'Match' was chosen as 'Mosaic Colormap Mode' because this option takes into consideration all the colormaps during the process of mosaicking and if all possible values are already used (for the bit depth), it attempts to match the value with the closest color that is available.

\section{Reclassification of satellite Images}

Each Landsat scene is a rectangle raster image rotated by certain angle. However, ArcMap cannot input rotated raster scene. In ArcMap, raster scene is inputted in a rectangle 
(a)

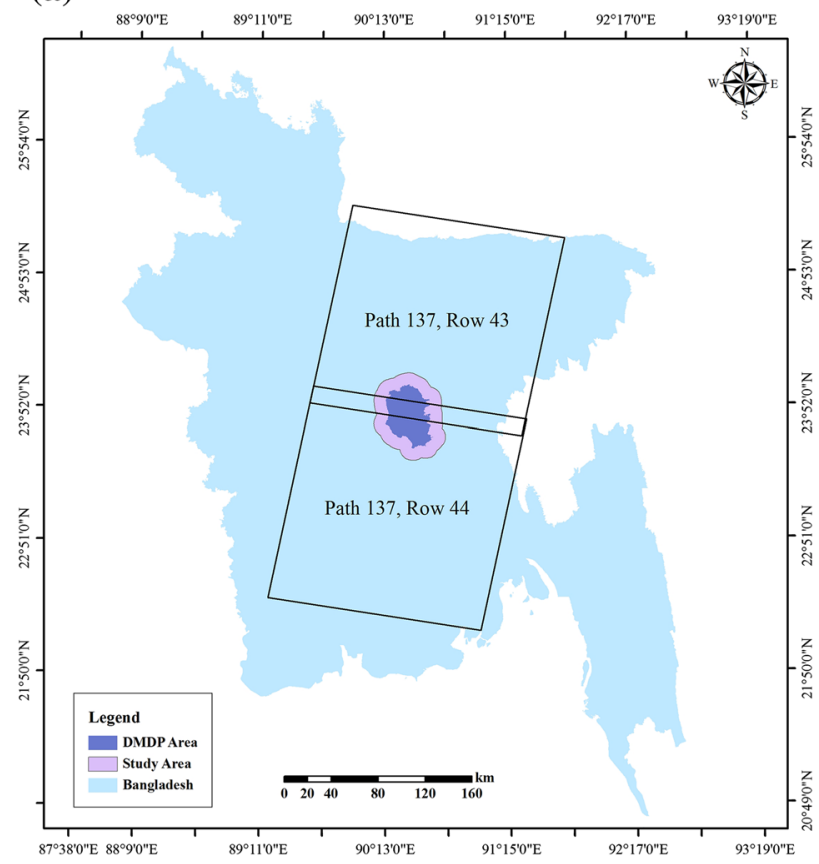

(b)

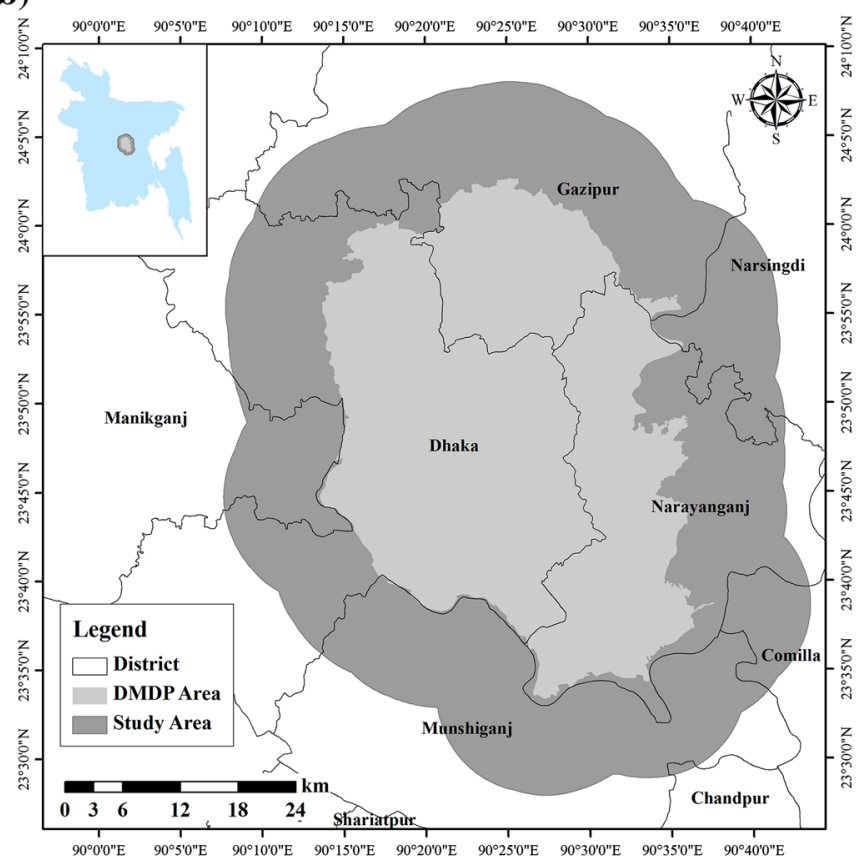

Fig. 1 a Study area with Landsat path and row; b study area

Table 1 Satellite images used in the study

\begin{tabular}{llllll}
\hline Type of satellite images & Spatial resolution (m) & Image source & Date of acquisition & Representative year & Remarks \\
\hline Landsat-5 Thematic Mapper & 30 & GLCF & $04-11-1989$ & 1989 & Same season but 2 years gap \\
Landsat-5 Thematic Mapper & 30 & GLCF & $26-11-1991$ & & Same season but 1 year gap \\
Landsat-5 Thematic Mapper & 30 & GLCF & $24-11-1999$ & 1999 & \\
Landsat-5 Thematic Mapper & 30 & GLCF & $25-10-2000$ & & 2010 \\
Landsat-5 Thematic Mapper & 30 & SPARRSO & $30-01-2010$ & & \\
\hline
\end{tabular}

shape with the rotated raster fitted obliquely within this rectangle. Therefore, Landsat scene becomes an unrotated rectangle containing ' 0 ' values where there is no $\mathrm{DN}$ value. For further remote sensing analysis, ' 0 ' values will create complexity in understanding and interpreting the other values. Hence, it is important to omit ' 0 ' value with the help of reclassification where ' 0 ' values are replaced by 'NoData' in ArcMap. While doing reclassification, the reclass field was 'Value.' In the reclassification section, 'Unique' was chosen which created a remap table that mapped 0 to less than 1 as 0,1 to less than 2 as 1,2 to less than 3 as 2 and continued up to 255 and above as 255 . The old value ' 0 ' was mapped to the new value 'NoData.'

\section{Mapping land cover}

\section{Mapping vegetation}

Enhancing vegetation information in satellite imagery is usually done with vegetation index. Vegetation index is the ratio of near-infrared (NIR) band (790-890 nm wavelengths) to a red band (610-680 $\mathrm{nm}$ wavelengths). High vegetation reflectance in NIR spectral range such as band 4 and high pigment absorption of red light such as band 3 condition the enhancement of vegetation (Jensen 2000). In this study, Soil Adjusted Vegetation Index (SAVI) was used to detect vegetation features because it has advantages over Normalized Difference Vegetation Index (NDVI). SAVI can be successfully applied in urban areas with low plant cover. SAVI can work with relative effectiveness in the area with plant cover as low as $15 \%$, while NDVI can only work effectively in the area with plant cover above $30 \%$. The SAVI was calculated using the following equation (Huete 1988)

$\mathrm{SAVI}=(\mathrm{NIR}-\mathrm{Red})(1+l)(\mathrm{NIR}+\operatorname{Red}+l)^{-1}$

$l$ represents correction factor ranging from 0 for very high densities to 1 for very low densities (Xu 2007). On an average, the value of $l$ was used as 0.5 in this study to produce enhanced vegetation image because the study 
region has an intermediate vegetation density. SAVI produced a continuous image. This image was recoded with ' 0 ' assigned to the pixels having negative value, since only positive pixel values are representative of vegetation. The recoding was done by following expression in 'Raster Calculator'

Recoded image $=\operatorname{CON}([$ Original image $]$

$$
<0.0,0.0, \text { [Original image]) }
$$

This recoding also facilitated the identification of an optimum threshold value. Theoretically, all the positive pixels should indicate vegetation, but this is not necessarily the case. Sometimes, other land covers specially the wetland can be indicated by positive values. To get over this uncertainty, this paper employed semiautomatic segmentation approach to determine an optimum threshold value over which the positive values successfully indicated vegetation. This threshold value was determined using 'Double-Window Flexible Pace Search' (DFPS) technique. Before using DFPS method, the recoded image was normalized into $(0,255)$ with following equation

$N=\left(T-T_{\min }\right)\left(T_{\max }-T_{\min }\right)^{-1} \times 255$

where $N=$ pixel value of normalized image, $T_{\max }=$ maximum pixel values of inputted image and $T_{\min }=$ minimum pixel values of inputted image. After the normalization of the images, optimum threshold was determined. The pixels having values over the determined threshold value thus indicated vegetation.

\section{Mapping wetland}

Modified Normalized Difference Water Index (MNDWI) was used to extract water body. This index detects the water bodies by a ratio of Green band $(500-590 \mathrm{~nm}$ wavelengths) to middle infrared (MIR) band (3,000$5,000 \mathrm{~nm}$ wavelengths). This index takes advantage of high water reflectance in Green band and high vegetation and soil reflectance in MIR band. In this study, MNDWI was prioritized over Normalized Difference Water Index (NDWI) because with NDWI, built-up areas may sometimes have positive value creating intricacy in mapping water features correctly. In contrary, MNDWI index assigns negative value to built-up features thus separates built-up areas from wetlands. Following equation was used to calculate MNDWI (Xu 2005).

MNDWI $=($ Green - MIR $)(\text { Green }+ \text { MIR })^{-1}$

Similarly, the derived MNDWI was a continuous raster which was also recoded using Eq. (2) to create an image with ' 0 ' value assigned to the negative pixels, as only positive pixels theoretically represent wetland. Following the recoding of image, it was normalized into $(0,255)$ using Eq. (3). After that, an optimum threshold value was identified using DFPS method above which all the pixels indicated wetland with increased accuracy.

\section{Mapping built-up area}

To extract built-up area, both NDVI and NDBI were utilized. Built-up area can be enhanced using NDBI only. With NDBI, the high reflectance in NIR band is subtracted from the high reflectance in MIR band, thus remaining reflectance value is enhanced which indicates built-up features. In this study, instead of original NDBI approach, modified NDBI approach was used proposed by He et al. (2010) with slight but useful extension. In original NDBI approach, the builtup index is derived by subtracting the binary NDVI from binary NDBI. But in this approach, continuous NDVI is subtracted from continuous NDVI. In this way, accuracy is increased by the application of DFPS approach to obtain the optimum threshold to map the built-up features.

Derivation of NDVI raster image At first, a continuous NDVI image was created by the following equation (Zha et al. 2003; Zhang et al. 2005)

$\mathrm{NDVI}=(\mathrm{NIR}-\mathrm{Red})(\mathrm{NIR}+\mathrm{Red})^{-1}$

In this study, to facilitate the subsequent process, the derived continuous NDVI image was recoded to create an image with ' 0 ' value assigned for all pixels having negative indices. Recoding was not proposed in the modified NDBI approach. However, if the negative values are not omitted from both NDVI and NDBI, the subtraction of smaller negative value of NDVI from larger negative value of NDBI can possibly produce positive values and thereby indicate built-up areas incorrectly. Recoding of the images will nullify this possibility.

Derivation of NDBI raster image After deriving NDVI, Normalized Difference Built-up Index (NDBI) was calculated to create a continuous NDBI image by following equation (Zha et al. 2003).

$\mathrm{NDBI}=(\mathrm{MIR}-\mathrm{NIR})(\mathrm{MIR}+\mathrm{NIR})^{-1}$

Similarly, the derived continuous NDBI image was recoded to create an image with ' 0 ' value assigned for all pixels having negative indices. Theoretically, all the positive indices indicate the built-up features.

Built-up area mapping Following the derivation of NDVI and NDBI, a continuous built-up (BU) image was created by the following equation (He et al. 2010). 
$\mathrm{BU}=\mathrm{NDBI}-\mathrm{NDVI}$

The derived BU image was continuous image. In a similar way to vegetation and wetland mapping, this $\mathrm{BU}$ image was recoded with ' 0 ' assigned to the negative values. Then, the recoded image was normalized into $(0$, 255) and an optimum threshold was determined over which the pixels indicate built-up areas.

\section{Determining optimum threshold value: DFPS approach}

In this study, optimum threshold value was determined to map more accurately different land covers from satellite imagery using indices. Above the identified threshold value, the pixels indicate the expected land use. In order to overcome the problem of subjectivity and variability in determining threshold value, Chen et al. (2003) developed an algorithm called DFPS. This method includes identification of the threshold value from the training samples that contain all the possible changes; for example, in this study, the change is in the form of land cover change. The assumption is that the training samples are representative of the entire study area. Eventually, a threshold value leading to the maximum accuracy of change detection was identified as an optimum threshold value. There are different steps in DFPS approach, suggested by Chen et al. (2003), which were used in the study as described in the subsequent segments.

Selection of typical sample areas for land cover change After derivation of different index images, the original images and the derived images were compared to select the training samples containing change. In choosing training samples, visual interpretation was used to detect typical built-up areas, vegetation and wetland. In case where change pixels were not detectable by visual interpretation, Google Earth Image was used. The criteria for selecting training sample were as follows:

1. Training samples included only change pixels

2. Training samples were 'islands' encircled by nochange pixels.

Double-window flexible pace search approach to identify optimum threshold was applied separately for different index images which represent separate land cover class. For instance, in case of built-up index, training samples were to include only built-up pixels and were 'islands' encircled by non-built-up pixels. Therefore, the samples were of double window-where inner window contained change pixel and outer window contained no-change pixel. Similar criteria were considered for vegetation and wetland indices separately. After the training patches were selected, a buffer of 1 pixel was constructed around the patches. In order to keep $L_{k}$ in Eq. (9) from becoming negative, the outside border (outside window) was set to one pixel for each training patch. The total number of pixels within all the training patches was 2,000 .

Determination of the search range and pace The threshold search range was set as a difference between the maximum value and the minimum value of derived index images in the first search process. The first pace was calculated by following formula

$P_{1}=(b-a) m^{-1}$

where $P_{1}=$ pace in the first search process, $b=$ maximum value of index image, $a=$ minimum value of index image and $m=$ a positive integer indicating the number of potential thresholds in a search process which was set manually. The potential thresholds to detect the changed pixels from the training samples in the search process were given within the range of $(a, b)$ as $b-P_{1}, b-2 P_{1}$ and so on.

Calculation of test parameter The success rate of land cover mapping was defined to evaluate the performance of each potential threshold value during one search process for identifying land cover change/non-change pixels. The success rate was calculated for a potential threshold value by following equation

$L_{k}=\left(A_{k 1}-A_{k 2}\right) A^{-1} \times 100 \%$

where $L_{k}=$ success rate, $A_{k l}=$ number of land cover change pixels detected inside all the training patches (within inner boundary), $A_{k 2}=$ number of land cover change pixels detected incorrectly (within outer boundary) and $A=$ total number of pixels within all the training patches. After obtaining all the $L_{k}$ for all the $\mathrm{m}$ thresholds in one search, the maximum and minimum values of $L_{k}$, as found, were designated as $L_{\max }$ and $L_{\min }$ during this search process. If the two parameters do not satisfy the exit condition described in the fourth step, a new search begun. The new search range was set in the range $\left(k_{\max }-P_{1}, k_{\max }+P_{1}\right)$, and a new smaller search pace was set based on this search range with Eq. (8). Here, $k_{\max }$ is the potential threshold value corresponding to $L_{\max }$ in the search process.

Condition to exit the iteration The second and third steps of iterative process were terminated when the following equation is satisfied

$L_{\max }-L_{\min } \leq \delta$

$L_{\max }$ and $L_{\min }$ are the maximum and minimum values of the success rate in one search process. $\delta$ is an acceptable error constant. The threshold value corresponding to $L_{\max }$ was considered to be an optimal threshold value to extract the required land use from index images. In this study, the acceptable difference between the maximum and minimum 
success rate, i.e., $\delta$ was considered to be $2 \%$. The value of $\delta$ depends on the degree of precision the researchers want, the time and manpower they have. Smaller $\delta$ value thus requires more manpower and time to be defined.

Accuracy assessment of the land cover mapping: error matrix

In this study, multinomial test was performed to assess the accuracy of the land cover mapping. This test not only stipulates the error frequency but also detects the nature of the errors. This approach is based on the confusion matrix or error matrix. This matrix forms a table where the columns represent the reference (observed) land cover classes, and the rows represent the extracted (mapped) classes. Each cell in the matrix contains the number of the observations in the mapped class of its row that had been in fact observed in the class of its column. Thus, the diagonal of the matrix represents agreement between image and the ground. In this study, the user's accuracy, producer's reliability and overall accuracy were determined for each land cover classes. Following equations (Rossiter 2004) were used

$C_{i}=X_{i i} \times X_{i+}^{-1} \times 100 \%$

where $C_{i}=$ user's accuracy, mapped class $i, X_{i i}=$ number of observation in the diagonal of matrix and $X_{i+}=$ marginal sum of row (mapped class) $i$.

$O_{j}=X_{j j} \times X_{+j}^{-1} \times 100 \%$

where $O_{j}=$ producer's reliability, reference class $j$, $X_{j j}=$ number of observation in the diagonal of matrix and $X_{+j}=$ marginal sum of column (reference class) $j$.

$A_{o}=\sum X_{i i} \times N^{-1} \times 100 \%$

where $A_{o}=$ producer's reliability, reference class $j$ and $N=$ total number of observations. The error matrix was also evaluated with 'kappa' index. The kappa index was calculated using following formula

$K=\left(N \sum X_{i i}-\sum X_{i+} X_{+j}\right)\left(N^{2}-\sum X_{i+} X_{+j}\right)^{-1} \times 100 \%$

\section{Results and discussion}

Land cover in different years

After normalization of corresponding index raster image, the optimum threshold was identified using DFPS approach for 1989, 1999 and 2010. Since the maximum and minimum value of the derived images is same for SAVI, MNDWI and BU index for all the years, same search range and pace were set initially for 1989, 1999 and 2010. The initial search range was set to $(0,255)$ and the pace as 15 . Accordingly, the number of thresholds tested totaled 37. Eventually, the optimum threshold value of SAVI was determined as 113, 113 and 85 for the year of 1989, 1999 and 2010, respectively. The success rate was 70.30, 67.40 and $77.2 \%$ with the difference between maximum and minimum success rate, in the last search range, of $1,0.8$ and $0.7 \%$ for 1989, 1999 and 2010, respectively.

The optimum threshold value for mapping wetland in 1989, 1999 and 2010 was identified as 56, 56 and 198, respectively. The success rate was 75.60, 78.90 and $60.10 \%$, and the difference between maximum and minimum success rate in the last search range was $0.8,0.8$ and $1.8 \%$ for 1989,1999 and 2010, respectively.

To map built-up area for the year of 1989, 1999 and 2010 , optimum threshold value was found as 29,55 and 5 with the success rate of $69.10,80$ and $87.80 \%$, respectively. Difference between maximum and minimum success rate was $0.7,0.5$ and $0.3 \%$ in three years, respectively. Therefore, the pixels exceeding the determined threshold value successfully mapped the desired land cover in the satellite images (Fig. 2).

Accuracy assessment of land cover mapping in 2010

For the years of 1989 and 1999, aerial photography or other relevant high-resolution imagery of study area were not available. Therefore, it was not possible to assess the accuracy of the land cover mapping for 1989 and 1999 with the use of error matrix. However, the accuracy was assessed for the year of 2010 with the use of cost free high-resolution Google Earth satellite image through construction of error matrix. Firstly, a high-resolution (high enough to detect the boundary of single structures) Google Earth image was obtained and projected. The image had latitude and longitude with geographic coordinate system of World Geodetic System 1984 (WGS 84). This raster image was then projected to Universal Transverse Mercator (UTM) projection system for Zone $45 \mathrm{~N}$ (since Bangladesh falls into UTM Zone $45 \mathrm{~N}$ ). After projecting into UTM, the image was projected into Bangladesh Transverse Mercator (BTM) projection system. During this projection, WGS 84 was transformed to 'Everest Bangladesh 1937' geographic coordinate system with the help of Geocentric Translation using following parameters.

$\Delta \mathrm{X}=-283.729, \Delta \mathrm{Y}=-735.942, \Delta \mathrm{Z}=-261.143$

After the projection, samples were taken in the Google Earth satellite image. To construct an error matrix, total 150 samples were selected randomly according to the rule of thumb which urges that 50 samples should be selected 


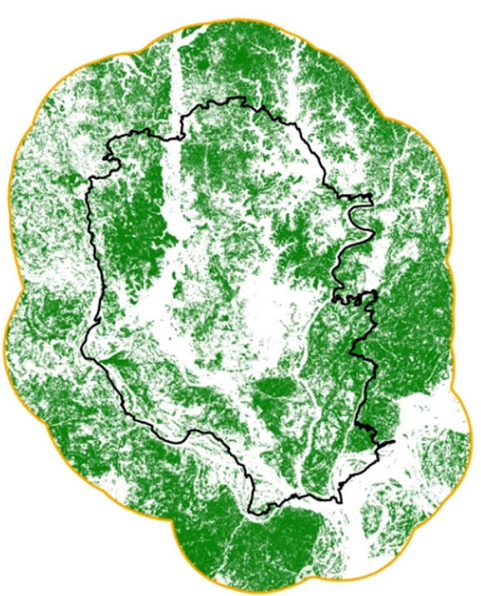

(a)

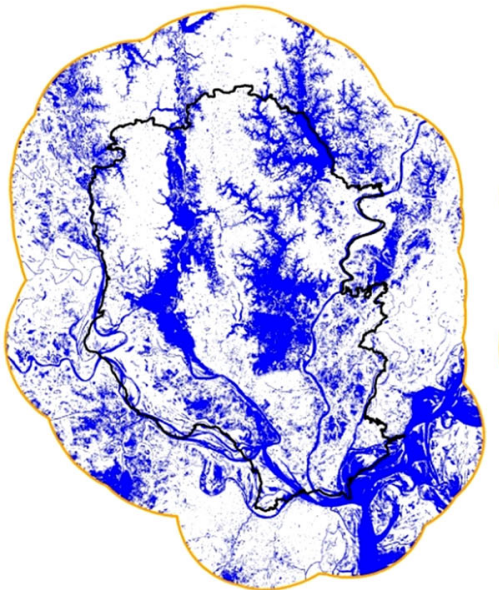

(d)

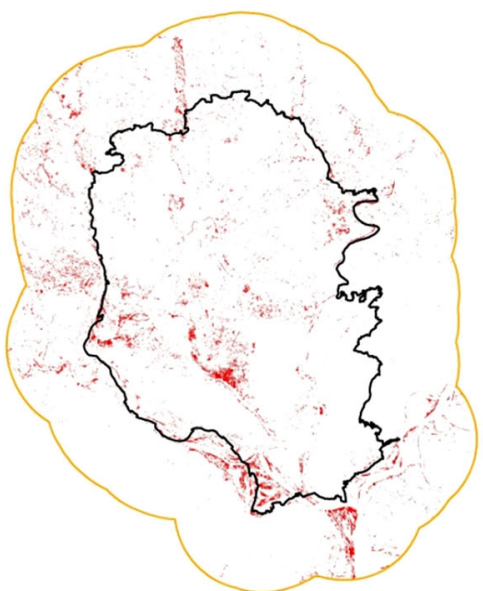

(g)

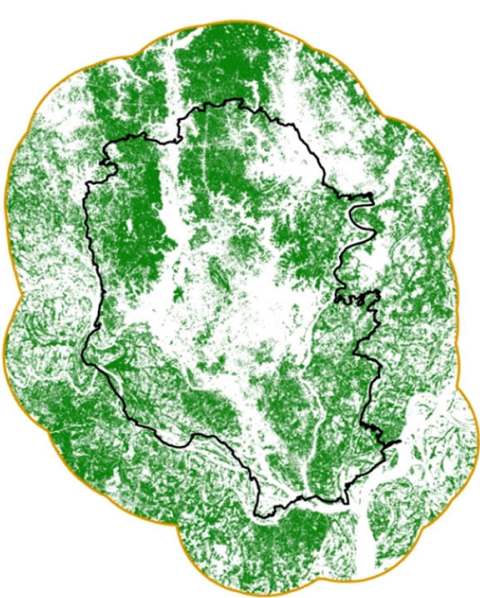

(b)

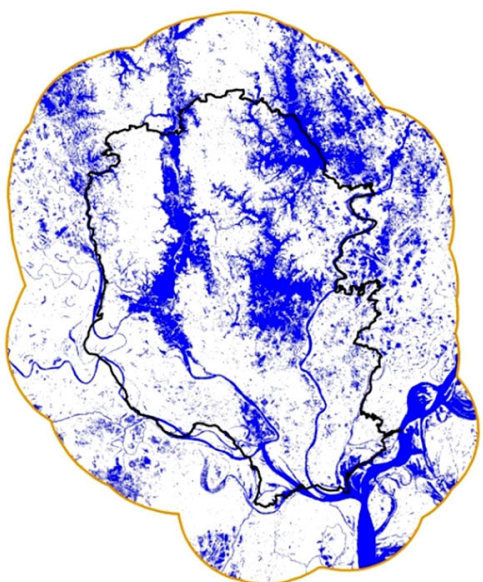

(e)

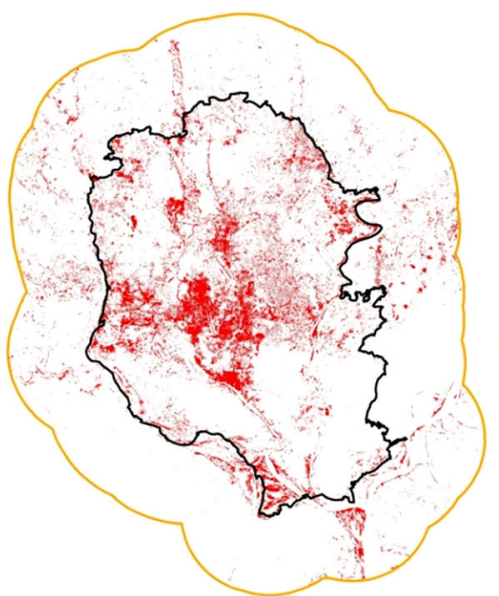

(h)

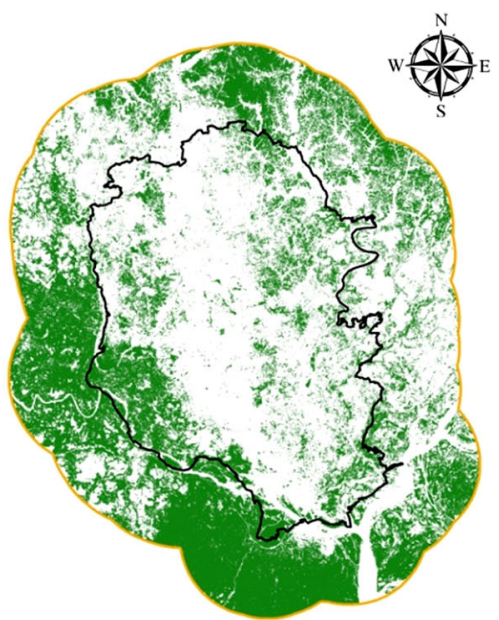

(c)

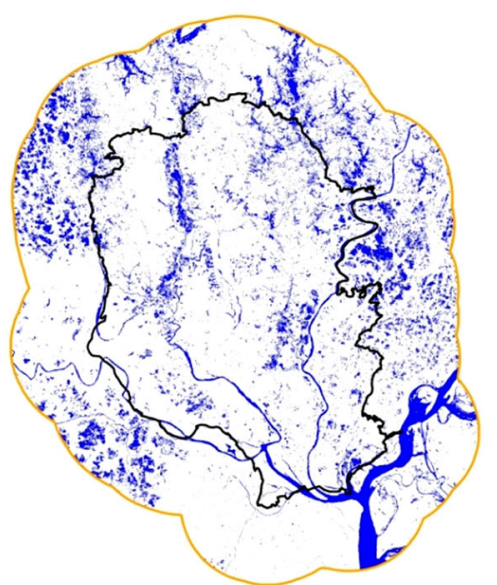

(f)

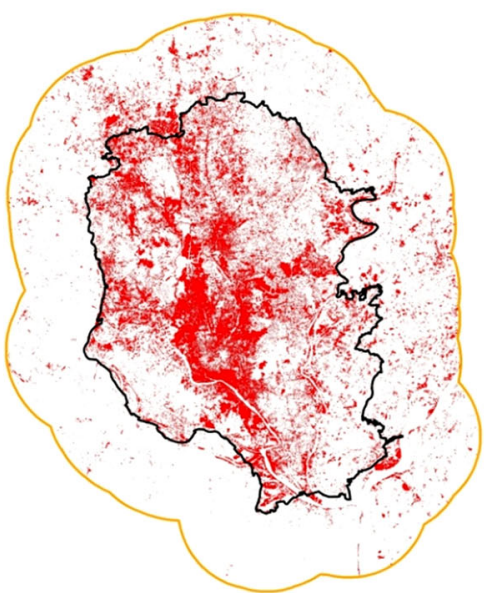

(i)

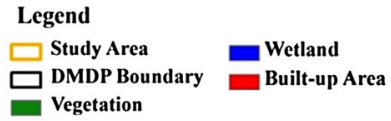

Fig. 2 Mapped vegetation in a 1989, b 1999 and c 2010; wetland in d 1989, e 1999 and f 2010; built-up area in g 1989 , h 1999 and i 2010 
Table 2 Error matrix for land cover mapping in 2010

\begin{tabular}{lccccc}
\hline & & \multicolumn{2}{l}{ Reference class (no. of pixels) } & Total \\
\cline { 3 - 5 } & & $\begin{array}{l}\text { Built- } \\
\text { up } \\
\text { land }\end{array}$ & Vegetation & Wetland & \\
\hline $\begin{array}{l}\text { Mapped class } \\
\text { (no. of } \\
\text { pixels) }\end{array}$ & $\begin{array}{c}\text { Built-up } \\
\text { land }\end{array}$ & 47 & 10 & 0 & 57 \\
& Vegetation & 2 & 61 & 0 & 63 \\
Total & Wetland & 2 & 1 & 27 & 30 \\
\hline
\end{tabular}

Table 3 Accuracy assessments of land cover mapping in 2010

\begin{tabular}{lllll}
\hline $\begin{array}{l}\text { Land } \\
\text { cover } \\
\text { classes }\end{array}$ & $\begin{array}{l}\text { User's } \\
\text { accuracy, } \\
\mathrm{C}_{\mathrm{i}}(\%)\end{array}$ & $\begin{array}{l}\text { Errors of } \\
\text { commission, } \\
\mathrm{C}^{*}(\%)\end{array}$ & $\begin{array}{l}\text { Producer's } \\
\text { accuracy, } \mathrm{O}_{\mathrm{i}} \\
(\%)\end{array}$ & $\begin{array}{l}\text { Errors of } \\
\text { omission, } \\
\mathrm{O}^{*}\end{array}$ \\
\hline $\begin{array}{l}\text { Built-up } \\
\text { land }\end{array}$ & 82.46 & 17.54 & 92.16 & $7.84 \%$ \\
$\begin{array}{l}\text { Vegetation } \\
\text { Wetland }\end{array}$ & 96.83 & 3.17 & 84.72 & $15.28 \%$ \\
\hline
\end{tabular}

for each land cover category (Congalton 1991; Congalton and Green 1999; Story and Congalton 1986). Based on these training samples, error matrix was constructed for 2010 satellite image which is shown in Table 2 and the calculation of accuracy assessment is shown in Table 3.

Producer's accuracy measures how well a specific land cover has been extracted and the proportion of correctly labeled features in the reference data. For example, determined producer's accuracy of built-up land means that $92.16 \%$ built-up lands are labeled correctly in the reference data. User's accuracy measures the reliability of the generated mapped classes and indicates the probability that a specifically extracted land cover also belongs to that specific land cover in reality. For instance, the determined user's accuracy of vegetation means there is a $96.83 \%$ probability that the detected vegetation in the image coincides with the ground class. The overall accuracy of the land cover extraction is $90 \%$, and the 'kappa' coefficient is 0.8421 , i.e., there is an $84.21 \%$ agreement between the mapped and reference class.

Trend of land cover change from 1989 to 2010

All the three land cover classes both inside DMDP and the study area are shown in Fig. 3. If the area of built-up features, vegetation cover and wetland in the study area are compared, a trend of change in these major land cover classes can be clearly identified from 1989 to 2010 as shown in Table 4.

Table 4 explicitly shows that built-up area is increasing and both vegetation and wetland are decreasing. This increase and decrease are prevalent in each decade. From 1989 to 1999 , built-up area increased by $44.89 \%$ with an average increase of 592.1 acre per year. During the next decade from 1999 to 2010, the rate of increase in built-up area accounted for $40 \%$. During this decade, the built-up area increased by 757 acre per year. This increase clearly indicates the rate of urbanization. The initial pace of urbanization was comparatively higher during 1989 to 1999 as compared to the urbanization rate during 1999 to 2010. Hence, the overall increase in built-up areas from 1989 to 2010 was accounted for almost $102.27 \%$, i.e., more than double.

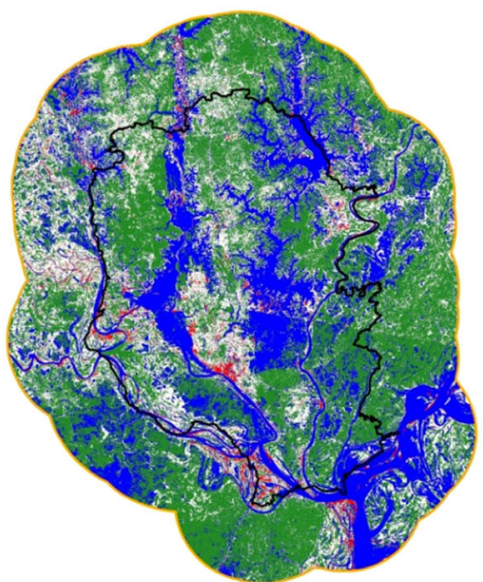

(a)

Legend

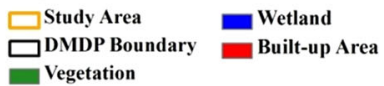

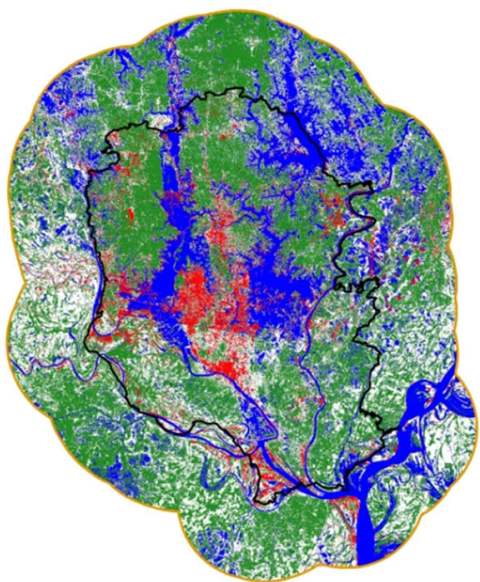

(b)

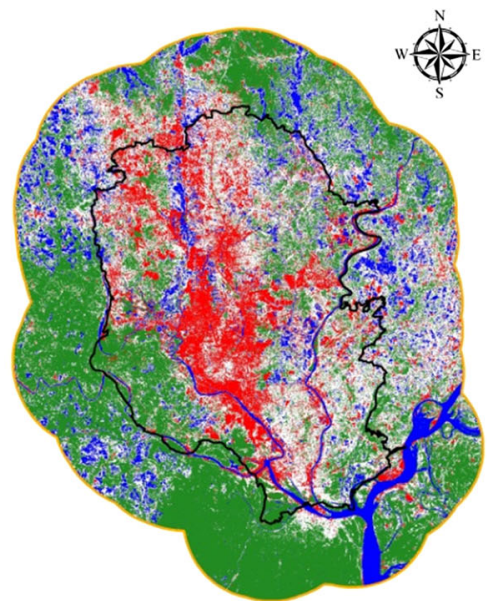

(c)

Fig. 3 Three mapped land cover classes in a 1989, b 1999 and c 2010 
Table 4 Trend of land cover change in study area from 1989 to 2010

\begin{tabular}{|c|c|c|c|c|c|c|}
\hline \multirow[t]{2}{*}{ Land use Classes } & \multicolumn{3}{|c|}{ Area in acre } & \multicolumn{3}{|c|}{ Increase or decrease in $(\%)$} \\
\hline & 1989 & 1999 & 2010 & From 1989 to 1999 & From 1999 to 2010 & From 1989 to 2010 \\
\hline Vegetation & 235,899 & 209,573 & 182,607 & -11.16 & -12.87 & -22.59 \\
\hline Wetland & 184,169 & 119,830 & 77,593 & -34.93 & -35.25 & -57.87 \\
\hline Built-up area & $13,191.10$ & $19,112.10$ & $26,681.10$ & 44.89 & 39.60 & 102.27 \\
\hline
\end{tabular}

Fig. 4 Trend of land cover change in study area from 1989 to 2010

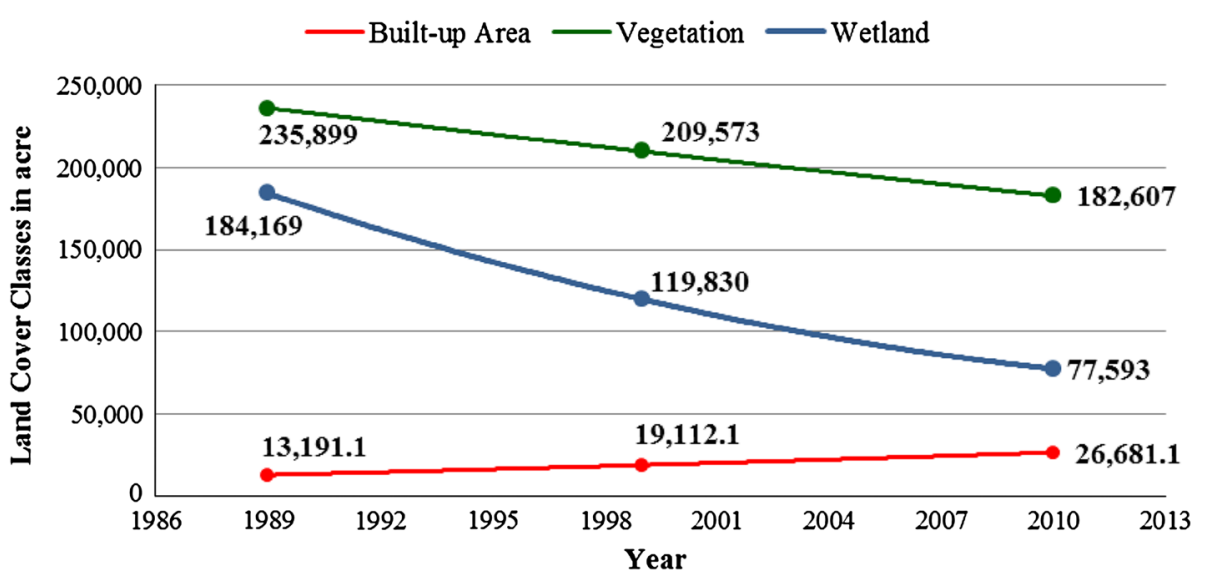

The increase in built-up area has a definite and direct contribution to a substantial decrease in vegetation and wetland in these years. The main reason is that area has been developed into built-up features by conversion of either wetland or agricultural land. From 1989 to 1999, the vegetation cover has decreased by an average rate of 2,632.6 acre per year. In the next decade from 1999 to 2010 , it has decreased by an average rate of 2,696.9 acre per year. Therefore, from 1989 to 2010 , vegetation decreased by more than $22 \%$. This trend clearly infers that agricultural land will also reduce in the following decades.

Over 20 years, the rate of decrease of water bodies has been higher as compared to the vegetation. From 1989 to 1999 , the water bodies in study area have decreased by an average rate of 6,434 acre per year. In the next 10 years from 1999 to 2010, wetland has decreased by an average rate of $4,223.7$ acre per year. On the whole, water bodies have decreased by $58 \%$ from 1989 to 2010 that is decreased to more than half of the amount. The overall trend of the land cover change from 1989 to 2010 is projected in Fig. 4.

\section{Conclusion}

Conventional land cover mapping, done by using different indices, does not go further with finding out exactly up to which pixel values land covers are correctly mapped. Therefore, all the positive values from derived index images are accepted to be representative of corresponding land covers. In this context, we used semiautomatic segmentation technique to identify the optimum threshold value to extract the desired land cover classes using double-window flexible pace search approach. This approach has previously been used to map built-up area. However, in this paper, we successfully presented that semiautomatic segmentation approach can also be used for SAVI and MNDWI.

Besides, we presented a detail process of accuracy assessment technique for land cover mapping using Google Earth satellite image in replacement of the expensive aerial photography or other high-resolution satellite imagery. Error matrix of accuracy assessment in this study presents 82.46, 96.83 and $90 \%$ user's accuracy of mapping built-up area, vegetation and wetland, respectively. Research results support the average loss of vegetation and water bodies as dreadfully high as 2,664.6 and 5,328.8 acre per year (7.3 and 14.6 acre per day), respectively.

During the study, we were confronted with some limitations such as unavailability of same year satellite images and high-resolution aerial photography of the entire study area. Moreover, available high-resolution aerial photography or IKONOS satellite imagery for conventional accuracy assessment was beyond affordability. Despite all these limitations, we successfully accomplished the study using a diligent land cover mapping and accuracy assessment technique. Therefore, this study can expectantly be helpful for further research in the similar fields, for other territories and within analogous limitations. 
Acknowledgments The authors are indebted to the department of Urban and Regional Planning of the Bangladesh University of Engineering and Technology for providing necessary logistic supports to conduct this research. We are also grateful to the site GLCF: Earth Science Data Interface for access to their data. We also acknowledge the use of data provided by the Bangladesh Space Research and Remote Sensing Organization (SPARRSO).

\section{References}

Anderson JR, Hardy EE, Roach JT, Witmer RE (1976) A land use and land cover classification system for use with remote sensor data. United States Government Printing Office, Washington [online]. http://landcover.usgs.gov/pdf/anderson.pdf

Bhatta B (2009) Analysis of urban growth pattern using remote sensing and GIS: a case study of Kolkata, India. Int J Remote Sens 30:4733-4746

Campbell WG, Mortenson DC (1989) Ensuring the quality of geographic information system data: a practical application of quality control. Photogramm Eng Remote Sens 55:1613-1618

Chen J, Gong P, He C, Pu R, Shi P (2003) Land-use/land-cover change detection using improved change-vector analysis. Photogramm Eng Remote Sens 69(4):369-379

Cleve C, Kelly M, Kearns F, Moritz M (2008) Classification of the wildland-urban interface: a comparison of pixel- and objectbased classifications using high-resolution aerial photography. Comput Environ Urban Syst 32:317-326

Congalton RG (1991) A review of assessing the accuracy of classifications of remotely sensed data. Remote Sens Environ 37(1):35-46

Congalton RG, Green K (1999) Assessing the accuracy of remotely sensed data: principles and practices. Lewis Publishers, Boca Raton

European Communities (2001) Manual of concepts on land cover and land use information systems. Office for Official Publications of the European Communities, Luxembourg [online]. http://ec. europa.eu/eurostat/ramon/statmanuals/files/KS-34-00-407-_-IEN.pdf. Accessed 27 May 2013

Firl GJ (2010) Lesson 8: mosaicking and clipping landsat data. Tutorial conducted from Colorado State University, Fort Collins, Colorado, United States [online]. http://ibis.colostate.edu/ WebContent/WS/ColoradoView/TutorialsDownloads/CO_RS_ Tutorial8.pdf. Accessed 19 Feb 2012

Griffiths P, Hostert P, Gruebner O, Van Derlinden S (2010) Mapping megacity growth with multi-sensor data. Remote Sens Environ 114:426-439

Guindon B, Zhang Y, Dillabaugh C (2004) Landsat urban mapping based on a combined spectral-spatial methodology. Remote Sens Environ 92:218-232

He C, Shi P, Xie D, Zhao Y (2010) Improving the normalized difference built-up index to map urban built-up areas using a semiautomatic segmentation approach. Remote Sens Lett 1(4):213-221

Huete AR (1988) A Soil-adjusted Vegetation Index (SAVI). Remote Sens Environ 25(3):295-309

IRIN (2012) Bangladesh: Dhaka's shrinking wetlands raise disaster risks. Humanitarian news and analysis. IRIN News [online]. http://www.irinnews.org/Report/95671/BANGLADESH-Dhakas-shrinking-wetlands-raise-disaster-risks. Accessed 21 June 2012

Janssen LLF, Vander Wel FJM (1994) Accuracy assessment of satellite derived land-cover data: a review. Photogramm Eng Remote Sens 60:419-426

Jensen JR (2000) Remote sensing of the environment: an earth resource perspective. Prentice Hall, Upper Saddle River, p 544
Lunetta RS, Ediriwickrema J, Johnson DM, Lyon JG, McKerrow A (2002) Impacts of vegetation dynamics on the identification of land-cover change in a biologically complex community in North Carolina, USA. Remote Sens Environ 82:258-270

Maling DH (1989) Measurements from maps-principles and methods of cartometry. Pergamon Press, Oxford

Muller SV, Walker DA, Nelson FE, Auerbach NA, Bockheim JG, Guyer S, Sherba D (1998) Accuracy assessment of a land-cover map of the Kuparuk River Basin, Alaska: considerations for remote regions. Photogramm Eng Remote Sens 64(6):619-628

Priyodesk (2011) Move to protect arable land now in cold storage. Priyo News [online]. http://news.priyo.com/politics/2011/10/08/ move-protect-arable-land-now-c-39572.html. Accessed 9 Nov 2012

Rogan J, Chen DM (2004) Remote sensing technology for mapping and monitoring land-cover and land-use change. Prog Plan 61:301-325

Rossiter DG (2004) Technical note: statistical methods for accuracy assessment of classified thematic maps [online]. http://www.itc. nl/ rossiter/teach/R/R_ac.pdf. Accessed 9 Jan 2013

Rouse JW, Haas RH, Schell JA, Deering DW (1974) Monitoring vegetation systems in the great plains with ERTS. In: Proceedings of the Third ERTS-1 Symposium, NASA Goddard, NASA SP-351, pp. 309-317

Sanderson (2000) Introduction to remote sensing. New Mexico Space Grant Consortium [online]. http://faculty.kfupm.edu.sa/crp/ bramadan/crp514/readings/\%20Introd_Remote_Sensing_Dr_ Sanderson_New_Mexico_State_Univ_38Pages.pdf

Shubho MTH, Hassan MT, Hossain MR, Neema MN (2013) Quantitative analysis of spatial pattern of dustbins and its pollution in Dhaka City-a GIS based approach. Asian Trans Eng 3(4):1-7

Smits PC, Dellepiane SG, Schowengerdt RA (1999) Quality assessment of image classification algorithms for land-cover mapping: a review and proposal for a cost-based approach. Int J Remote Sens 20:1461-1486

Story M, Congalton R (1986) Accuracy assessment: a user's perspective. Photogramm Eng Remote Sens 52(3):397-399

Turner BL, Skole DL, Sanderson S, Fisher G, Fresco LO, Leemans R (1995) Land-use and land-cover change. Science/Research Plan. Stockholm and Geneva: IGBP Report No. 35 and HDP Report No. 7

Wardad Y (2012) Enactment of agriculture land protection act underscored. The Financial Express [online]. http://www. thefinancialexpress-bd.com/more.php?date $=2012-01-15 \&$ news_ $\mathrm{id}=93985$. Accessed 7 June 2012

Xu H (2005) A study on information extraction of water body with the Modified Normalized Difference Water Index (MNDWI). J Remote Sens 9(5):511-517

$\mathrm{Xu} \mathrm{H}$ (2007) Extraction of urban built-up land features from landsat imagery using a thematic-oriented index combination technique. Photogramm Eng Remote Sens 72(12):1381-1391

$\mathrm{Xu} \mathrm{H}$ (2008) A new index for delineating built-up land features in satellite imagery. Int J Remote Sens 29:4269-4276

Yuan F, Bauer ME, Heinert NJ, Holden GR (2005) Multi-level land cover mapping of the Twin Cities (Minnesota) metropolitan area with multi-seasonal lands at TM/ETM+ data. Geocarto Inte 20(2):5-13

Zha Y, Gao J, Ni S (2003) Use of normalized difference built-up index in automatically mapping urban areas from TM imagery. Int J Remote Sens 24(3):583-594

Zhang Q, Pavlic G, Chen W, Fraser R, Leblanc S, Cihlar J (2005) A Semi-automatic segmentation procedure for feature extraction in remotely sensed imagery. Comput Geosci 31:289-296 